\title{
Terazosin Suppress Human Prostatic Cancer PC3 Cell Viability via Proteasome Inhibition
}

Shujue $\mathrm{Li}^{\#}$, Wenzheng $\mathrm{Wu}^{\#}$, Weidong $\mathrm{Ji}^{\#}$, Yeping Liang ${ }^{\#}$, Lili Oü, Guohua Zeng*, and Wenqi Wu*

Department of Urology, Minimally Invasive Surgery Center, The First Affiliated Hospital of Guangdong Key Laboratory of Urology, Guangzhou medical University, Guangdong, 510230, China

"Corresponding author: Guohua Zeng, Wenqi Wu, Department of Urology, Minimally Invasive Surgery Center, The First Affiliated Hospital of Guangdong Key Laboratory of Urology, Guangzhou Medical University, Guangdong-510230, China, Tel: 0086-020-34294145; E-mail: gzgyzgh@vip.tom.com; wwqwml@163.com

\#Equally contributed to this research work

Received date: May 22, 2014; Accepted date: June 12, 2014; Published date: June 19, 2014

Copyright: (c) 2014 Zeng, et al. This is an open-access article distributed under the terms of the Creative Commons Attribution License, which permits unrestricted use, distribution and reproduction in any medium, provided the original author and source are credited.

\begin{abstract}
Terazosin is one of classic quinazoline-based selective a1-adrenoreceptor antagonists, which is usually used for the treatment of benign prostate hyperplasia $(\mathrm{BPH})$ patients. Several evidences suggest that terazosin can induce apoptosis of prostatic cancer cells in vitro and suppress prostatic tumor growth in vivo, but molecular mechanism contributing to these processes has not yet been fully elucidated. In this study, we report that the suppression of terazosin on prostatic cancer PC3 cells viability partially mediated by proteasome inhibition. We first examined cytotoxicity of terazosin in human prostatic cancer cell line PC3, including cell viability, cell cycle analysis and cell apoptosis analysis. Then the chymotrypsin-like proteasome activity, levels of ubiquitinated-proteins and selective protein substrate of proteasome were detected, to reflect alteration of proteasome activity. Our results indicate that terazosin treatment results in a significant decrease of cell viability in a dose- and time- dependent manner in PC3 cells, accompanied with cell cycle arrest and apoptotic induction; Exposure to terazosin also causes a significant loss of proteasome activity as well as accumulation of ubiquitinated-proteins and selective protein substrate P27 in PC3 cells, which occurs prior to cell death. In view of these results, we conclude that terazosin suppress human prostatic cancer PC3 cell viability by cell cycle arrest and cell death induction, which is associated with its proteasome inhibitory activity.
\end{abstract}

Keywords: Terazosin; Prostatic cancer cell; Proteasome activity; Cell cycle; Cell death

\section{Introduction}

Prostatic cancer (PCa) is the most commonly diagnosed malignancy cancer in men worldwide. However, more than a half of patients are diagnosed with bone and lymph nodes metastasis predicated by pathologic or clinical evidence, or disturbed by progression from androgen-dependent cancer to androgenindependent cancer (CRPC) with more invasion and metastatic activity. Chemotherapy is still one of the main means for the treatment of CRPC, which is investigated to target prostatic cancer alone, or combine with other agents, to make CRPC cells undergo apoptosis effectively [1,2].

Terazosin is one of classic quinazoline-based selective a1adrenoreceptor antagonists, which is usually used for the treatment of benign prostate hyperplasia (BPH) patients. Moreover, several evidences suggest that terazosin can induce apoptosis and suppress growth of both androgen-sensitive and -insensitive human prostatic cancer cells in vitro and in vivo [3]. But the molecular mechanism contributing to these processes has not yet been fully elucidated only with a few reports on antitumor potency of terazosin of apoptotic induction and antiangiogenic action $[3,4]$, which need to be defined comprehensively.

Ubiquitin-proteasome pathway is one of important molecular targets of many chemotherapeutic agents, which has become a novel target for cancer therapy [5]. The proteasome is a primary multi catalytic-protease-complex for selective degradation of more than $80 \%$ intracellular proteins. The degradation is considered to be a key step in intracellular-proteins-recycling, which is defined as "non-lysosomal recycling" [6]. Dysfunction of the ubiquitin proteasome system will lead intracellular equilibrium to an indiscriminate environment, followed by cell growth inhibition and cell death. Several native and synthetic compounds have been investigated with proteasome activity inhibition [7], and they have some classic structures [8-14]. C-terminal furanyl substitution is one of the classic structures, which have been identified to contribute to proteasome inhibition with unique mechanism [15], so exploitation of proteasome inhibitory activities of more furan-contained compounds may be a work worth paying attention to.

Since the chemical structure of terazosin is also a C-terminal furancontained structure [16], which is considered to be one of classic structures of potential $20 \mathrm{~S}$ proteasome inhibitors. In this study, we present that terazosin can also inhibit proteasome activity which is one of the molecular mechanisms partially mediate suppressive action of terazosin on CRPC PC3 cell lines.

\section{Materials and Methods}

\section{Materials}

Annexin-V-FITC/PI apoptosis detection kit was purchased from Keygen Company (Nanjing, China). PC3 cell lines were purchased from ATCC. Anti-PARP antibody was purchased from Cell Signaling. 
Anti-Ubiquitin, anti-P27 and anti-GAPDH antibodies were purchased from Santa Cruz Biotechnology.

\section{Cell culture}

PC3 cells (purchased from ATCC) were cultured in F-12K medium (Gibco) with $10 \%(\mathrm{~V} / \mathrm{V})$ fetal bovine serum, and maintained at 37 with $95 \%$ humidified air and $5 \% \mathrm{CO}_{2}$.

\section{Cell viability assay}

$8 \times 10^{3}$ PC3 cells were plated in 96-well to incubated overnight, and treated with terazosin for the indicated periods. The plate was read in a microplate reader at 570/600 $\mathrm{nm}$ (VERSAmax; Molecular Devices) after staining with $10 \%$ Alamar blue solution for $4 \mathrm{~h}$. Analysis was performed on triplicate wells, and the data presented is representative of three independent experiments.

\section{Cell cycle analysis}

PC3 cells were treated with various concentrations of terazosin for the indicated periods. Cell cycle was measured by flow cytometry (FACSCalibur, BD), and data was analyzed.

\section{Cell death assay}

Cells were plated at a density of $2 \times 10^{5}$ cells/well in six-well plates and incubated overnight, and treated with $300 \mu \mathrm{M}$ terazosin at indicated points. Then cells were collected and washed, re suspended in $0.5 \mathrm{ml}$ of binding buffer, incubated with $2 \mu \mathrm{l}$ Annexin V-FITC dye and $5 \mu \mathrm{l}$ PI dye (Keygen, Nanjing, China) for $10 \mathrm{~min}$ in the dark. Cell death was detected using FACSCalibur flow cytometry and Western blot analysis for cleaved-PARP fragment. Cell death was detected using FACSCalibur flow cytometry and Western blot analysis for cleaved-PARP fragment.

\section{Peptidase activity assay}

Crude protein extracts ( $10 \mu \mathrm{g}$ protein) from the cultured cells were added to a total volume of $180 \mu \mathrm{l}$ reaction buffer $\left(\mathrm{p}^{\mathrm{H}} 7.4\right)$ containing HEPES $(25 \mathrm{mmol} / \mathrm{L})$, EDTA $(0.05 \mathrm{mmol} / \mathrm{L}), \mathrm{NP}-40$ (0.05\%), SDS $(0.001 \% \mathrm{w} / \mathrm{v})$ and the synthetic fluorogenic peptide Suc-LLVYaminomethylcoumarin (AMC) $(50 \mu \mathrm{mol} / \mathrm{L})$ for the proteasomal chymotrypsin-like activity. The reaction mixture was then incubated at 37 for $90 \mathrm{~min}$, and then fluorescence intensity of the free AMC was measured by a luminescence microplate reader (Varioskan Flash 3001, Thermo, USA). The excitation wavelength was $360 \mathrm{~nm}$ and the emission was $436 \mathrm{~nm}$, respectively.

\section{Western blot analysis}

Cells were seeded in 6-cm diameter dishes and incubated overnight, then treated with various concentrations of terazosin for the indicated periods. The cells were collected and washed, and solubilized with lysis buffer. Protein samples (30-120 microgram) were sparated by SDS/ PAGE (10\% gels) and transferred on to a nitrocellulose membrane (Millipore Corporation, Billerica). The membrane was incubated with anti-PARP (Cell Signaling), anti-ubiquitin, anti-P27 or anti-GAPDH (Santa Cruz Biotechnology) as primary antibodies, followed by incubation with horseradish peroxidase-conjugated IgG (Amersham Biosciences) as the secondary antibody. Then they were detected using the enhanced chemiluminescnce (ECL) detection reagents (Thermo, USA) and exposed to X-ray films (Kodak).

\section{Data Analysis}

All the experiments were done in triplicate and quantitative data are presented as mean \pm SEM. Comparisons of the data among different treatments were evaluated by one-way ANOVA with Dunnett's post hoc test using SPSS software version 13.0 and $\mathrm{P}$ values $<0.05$ were considered statistically significant.

\section{Results}

\section{Terazosin suppresses viability of prostatic cancer cell PC3}

PC3 cells were treated with various concentrations of terazosin for $48 \mathrm{~h}$, followed by staining with alamar blue and measurement at indicated wavelength. The results showed that terazosin can potently decrease viability of PC3 cells in a dose-depentdent manner, and the significant inhibition was identified when cells were treated with a dose higher than $50 \mu \mathrm{M}$ terazosin (Figure 1).

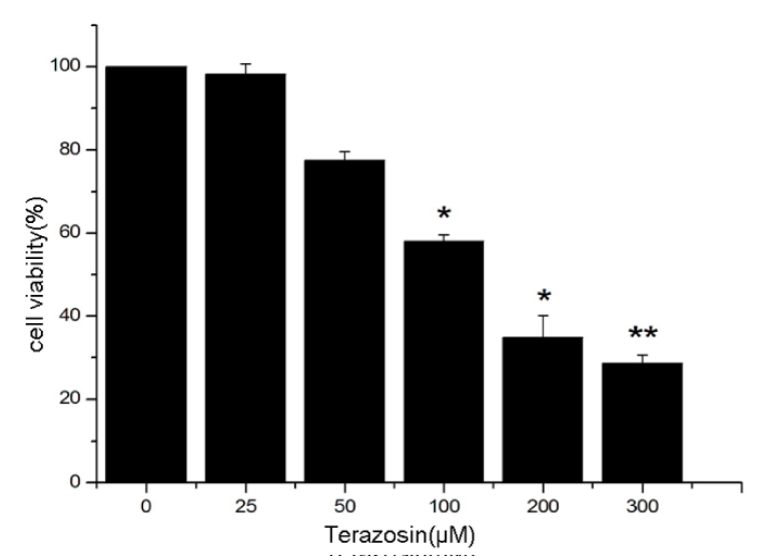

Figure 1: Terazosin inhibits cell viability of PC3 cells in a dosedependent manner. PC3 $\left(8 \times 10^{3}\right.$ cells/well $)$ cells were plated in 96well plate and exposed to different concentrations of terazoain for $48 \mathrm{~h}$, followed by Alamar blue assay. $\mathrm{N}=3$ independent experiments for each bar; ${ }^{\star}=\mathrm{P}<0.05$ vs. control.

\section{Terazosin induces cell cycle arrest at G0-G1 phase in PC3 cells}

As cell cycle arrest is one of important influences of cell viability, we analyzed distribution of cell populations in different phases of cell cycle after terazosin treatment.

PC3 cells were treated with $0-300 \mu \mathrm{M}$ terazosin for $24 \mathrm{~h}$, followed by PI staining and flow cytometer detection. The result of flow cytometry indicated that terazosin can induce G0-G1 phase arrest significantly in a dose-dependent manner (Figure 2A), and a time-dependent manner of cell cycle arrest was also shown after PC 3 cells were exposed to 300 $\mu \mathrm{M}$ terazosin for indicated hours (Figure $2 \mathrm{~B}$ ), the percent of cells at G0-G1 phase increased from $54.86 \%$ to $74.72 \%$. 

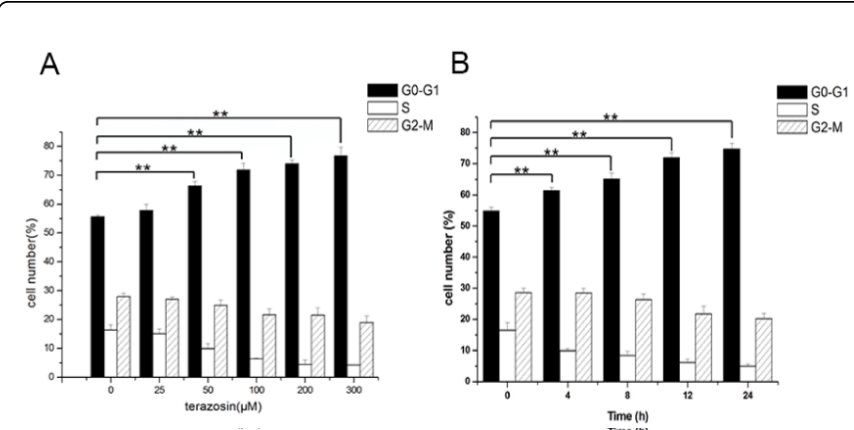

Figure 2: Terazosin induces cell cycle arrest in PC3 cells. PC3 cells were exposed to $0-300 \mu \mathrm{M}$ terazosin for $24 \mathrm{~h}(\mathrm{~A})$ and to $300 \mu \mathrm{M}$ terazosin for indicated hours (B), followed by PI staining and flow cytometer detection. Cell cycle was analyzed by cell cycle software. $\mathrm{N}=3$ independent experiments for each $\mathrm{bar} ;{ }^{*}=\mathrm{P}<0.05$ vs. control.

\section{Terazosin induces cell death in PC3 cells}

Since most of cell viability inhibition is also dependent on cell death induction, we next measured cell death in PC3 cells after terazosin treatment, with annexin V-FITC/PI co-staining and flow cytometry was performed subsequently. As shown in figure $4 \mathrm{~B}, 300 \mu \mathrm{M}$ terazosin incubating for $36 \mathrm{~h}$ could cause significant apoptosis in PC3 cells, and this apoptotic- induction became stronger with time extending. Cleaved-PARP fragment detecting was also performed to reflect apoptotic-inducing activity of terazosin, and results of western blotting analysis revealed significant increased levels of cleaved-PARP fragment in terazosin (more than $200 \mu \mathrm{M}$ )-treated cells compared with DMSO-treated cells (Figure 3B). Data above indicated that terazosin can sensitize PC3 cells to apoptosis, which is served to one cause of cell viability suppression.

\section{Terazosin causes proteasome inhibition in PC3 cells}

A furan-structure has been shown to be involved in some $20 \mathrm{~S}$ proteasome inhibitor, we next designed this study to investigate if terazosin is able to inhibit proteasome activity and if proteasome activity inhibition is one of molecule mechanisms mediate anti-cancer cell activity of terazosin. We detected chymotrypsin-like proteasome activity using the synthetic fluorogenic peptide Suc-LLVYaminomethylcoumarin (AMC). In PC3 cells, treatment with 25, 50, 100,200 and $300 \mu \mathrm{M}$ terazosin last for $48 \mathrm{~h}$ can cause about $4 \%, 12 \%$, $21 \%, 40 \%, 45 \%$ chymotrypsin-like proteasome activity inhibition, respectively (Figure $3 \mathrm{~A}$ ). In accordance with chymotrypsin-like proteasome activity inhibition, polyubiquitinated-proteins, which were tagged by polyubiquitins but not degraded by proteasome promptly because of decreased proteasome activity, were also accumulated (Figure 3B).

These results indicated that terazosin could induce proteasome inhibition in PC3 cells, but kinetic experiments were still need to determine the certain sequence existed between proteasome inhibition and cell death.

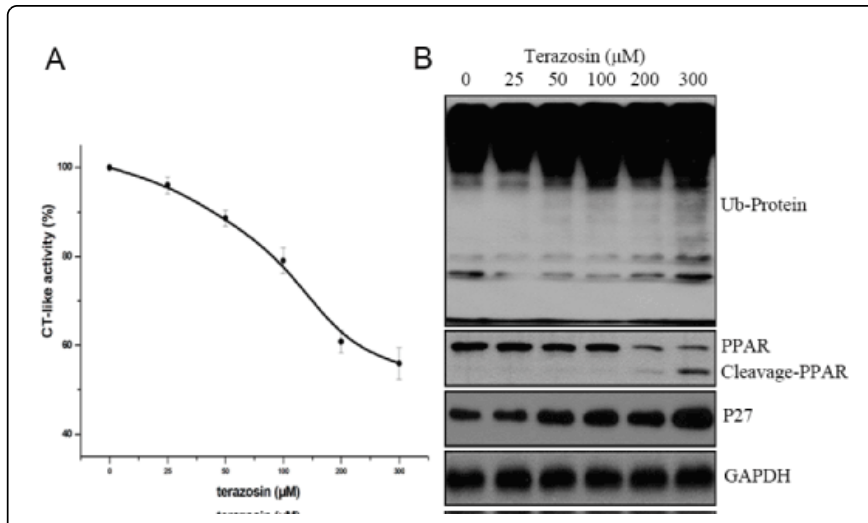

Figure 3: Terazosin inhibits proteasome activity and exhibits cytotoxic effect in a dose-dependent manner in cultured PC3 cells. (A) Inhibition of chymotrypsin-like activity by terazosin. PC3 cells were treated with $0-300 \mu \mathrm{M}$ terazosin for $48 \mathrm{~h}$, then crude proteins were extracted and followed by measurement of the fluorescence intensity of the free AMC. ${ }^{*}=\mathrm{P}<0.05$ vs. control. (B) PC 3 cells were treated with $0-300 \mu \mathrm{M}$ terazosin for $48 \mathrm{~h}$, followed by Western blotting analysis. Molecular weight of full length PARP is $110 \mathrm{kDa}$, and the cleaved fragment of PARP is $85 \mathrm{kDa}$. The image is a representative immune blot from three independent experiments yielding similar results. GAPDH was used as loading control.

\section{Proteasome activity inhibition precedes cell death induction}

We performed Kinetic experiments to judge whether proteasome activity inhibition precedes cell death induction. PC3 cells were treated with $300 \mu \mathrm{M}$ terazosin for indicate hours up to $48 \mathrm{~h}$, then we detected cell death using flow cytometry, chymotrypsin-like proteasome activity using fluorescence measurement of proteasome substrate, and levels of ubiquitinated proteins, cleaved-PARP fragment, P27 (target substrate protein of proteasome) were detected by western blotting analysis, respectively. In PC3 cells, as early as $8 \mathrm{~h}$ after $300 \mu \mathrm{M}$ terazosin treatment, chymotrypsin-like proteasome activity was inhibited significantly (Figure 4A) meanwhile polyubiquitinated-proteins and P27 were also accumulated (Figure 5). Contrast to the previous proteasome activity inhibition, results of flow cytometric measurement and western blotting analysis shown that both of Annexin V-FITCpositive cells and cleaved-PARP fragments were obviously detected as later as $36 \mathrm{~h}$ after $300 \mu \mathrm{M}$ terazosin treatment (Figures $4 \mathrm{~B}$ and 5).

These data revealed that proteasome activity inhibition precede induction of cell death in PC3 cells exposed to terazosin, suggesting that proteasome activity inhibition is one of molecular mechanisms of cell death induced by terazosin.

\section{Discussion}

Terazosin is a quinazoline-based a1-adrenoreceptor antagonist, which is widely used to relieve lower urinary tract symptoms [17]. Several further lines of evidence suggest that they possess the ability to suppress prostate tumor growth in vivo and their effects to decrease the viability of androgen-independent prostate cancer cells PC3 [18]. This apoptotic effect is a1-adrenoreceptor-independent, because transfection-mediated overexpression of al-adrenoreceptor resulted in no significant change of prostate cancer cells sensitivity to apoptotic induction, and these actions have been identified to be specific for 
quinazoline-based antagonists, other than other subtypes of a1adrenoreceptor antagonists such as the sulfonamide-based antagonist tamsulosin, an agent with a distinct chemical structure [19]. The signaling mechanisms of antitumor effect of doxazosin have been identified, involving increase in Bax expression, activation of TGF- $\beta$ and I $\kappa B$ [20], reduction in focal adhesion kinase [21], inhibition of protein kinase $\mathrm{B} / \mathrm{Akt}$ activation [22], and induction of death receptormediated apoptosis [23]. However, there are only a few reports on antitumor potency of terazosin except apoptotic induction and antiangiogenic action, the molecular mechanism mediate tumor cell cytotoxicity of terazosin is still not identified comprehensively. So we carried out this study to further discover molecular mechanisms underlying cell viability suppressing effect of terazosin.

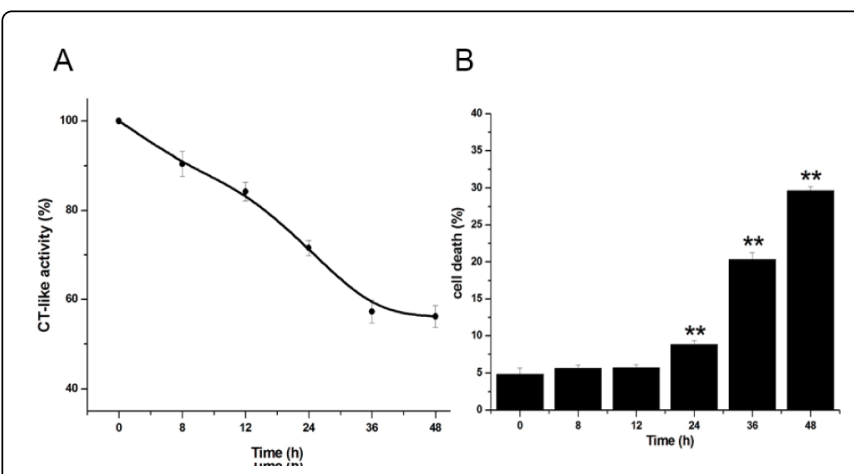

Figure 4: Proteasome inhibition mediated by terazosin occurs prior to induction of apoptosis. PC3 cells were treated with $300 \mu \mathrm{M}$ terazosin for the indicated periods. Chymotrypsine-like proteasome activity was analyzed (A) and Cell death was analyzed by flow cytometry (B). $\mathrm{N}=3$ independent experiments for each bar; ${ }^{*}=\mathrm{P}<0.05$ vs. control.

The abnormal ubiquitin-proteasome system plays a decisive role in cancer development is worldwide recognized [7]. Some classic structures of native and synthetic proteasome inhibitor have been identified, including $\alpha$-keto carbonyl [8], boric acid [9], vinyl sulfone [10], vinyl $\alpha, \beta$-unsaturated acyl peptidyl [11], epoxy ketone [12-14] et al. A recent report indicated that the C-terminal furanyl substitution may contribute to $20 \mathrm{~S}$ proteasome inhibition with unique mechanism [15] Since terazosin also possess a furan-based structure, we carried out this study to investigate whether terazosin can inhibit $20 \mathrm{~S}$ proteasome activity and whether this inhibitory effect mediate antitumor activity of terazosin against prostatic cancer cell or not.

We exposed CRPC PC3 cell lines to terazosin for indicated hours, and results of alamar blue assay showed that terazosin can inhibit cell viability with the IC50 value of about $130 \mu \mathrm{M}$ (Figure 1), which is according to other previous reports [4,24]. Cell cycle progression are regulated by cyclins, CDKs (cyclin dependent kinases), CKIs (CDK inhibitors), and DNA repair enzymes etc. P27Kip1 is one of important CKIs, which are significant deficient in several cancer tissues [25]. P27Kip1-up-regulating could serve as a "weapon" to concentrate cells at G0-G1 phase and in turn decelerate cancer cells' proliferation. Although some studies showed that terazosin could not affect prostatic cancer cell proliferation [3], many studies have shown that terazosin can arrest prostatic cancer cells at G0-G1 phase with increasing levels of p27KIP1[26,27]. Data obtained from our cell cycle analyze suggested that terazosin can significantly induce G0-G1 phase arrest in a dose- and time-dependent manner in PC3 cells.

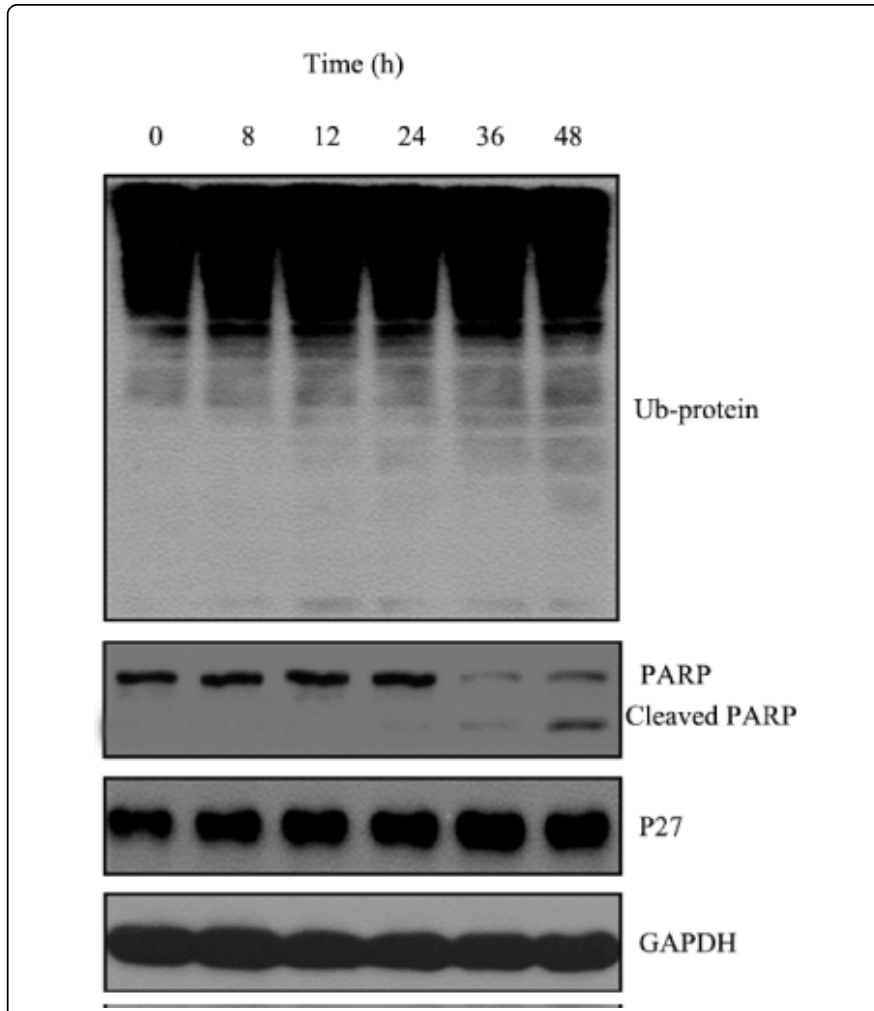

Figure 5: Accumulation of ubiquitinated-proteins and selective protein substrate occurs prior to appearance of cleaved-PARP fragment. PC3 cells were treated with $300 \mu \mathrm{M}$ terazosin for the indicated periods, then rude proteins were extracted and followed by Western blotting analysis. The image is a representative immune blot from three independent experiments yielding similar results. GAPDH was used as loading control.

Ubiquitin-proteasome-pathway (UPS) has been explored as a pivotal post-translational modification (PTM) for cell cycle regulatory proteins [28-31]. Therefore, proteasome inhibitor can restrict cell division through proteasome inhibition and subsequent weaken cell cycle regulatory proteins degradation in cancer cells [32,33]. In this study, we also observed up-regulation of P27Kip1, accompanied with accumulation of other ubiquitinated proteins, which were possibly ascribed to the milder protein degradation activity of UPS after terazosin exposure and took majority responsibility for cell cycle arrest. Although more crosstalks of cell cycle regulatory proteins and transcription factors with proteasome activity inhibition are still needed to investigate to consummate molecular mechanisms underlying cell cycle regulating of terazosin.

We also detected the down-regulation of proteasome activity, accumulation of ubiquitinated-proteins and selective protein substrate P27Kip1, and apoptosis in PC3 cells after terazosin treatment, and a kinetic study was carried out to clarify possible relationship between proteasome activity inhibition and cell apoptosis after terazosin treatment. Our data shown that terazosin can reveal inhibit proteasome activity as well as cell survival in a time-dependent manner, but these influences were not isochronous suggesting that proteasome activity inhibition caused by terazosin may partially mediated the subsequent cell apoptosis. 
Our results here have revealed the inhibition characteristic of terazosin on proteasome activity. However, this study is restricted on account of the weak effects of terazosin on prostatic cancer with an IC50 of about 130 micro molar and only CRPC PC3 cell line was observed, further medicinal chemistry modifications and more in vivo experiments are needed to proof this molecular mechanism. Besides on many reports focus on combination of terazoain with other agents on LUT/BPH patients [34-37], Chang et al. also showed that combination of teazosin and genistein was more effective in inhibiting prostate cancer DU145 cells growth and inducing apoptosis than either alone [38]. Since proteasome activity inhibitory effect has been known to sensitize tumor cells to apoptosis [39-41] and autophagy [42], terazosin may prospectively be used in combination with lowerdosage of other anti-prostatic cancer drugs to improve therapeutic efficiency by proteasome activity inhibition.

\section{Conflict of Interests}

The authors declare that there is no conflict of interests.

\section{Acknowledgements}

This work was supported in part by funds from Guangzhou medical University Foundation (NO. 2010A05) and Bureau of Health of Guangzhou Municipality Foundation (NO. 201122231015).

\section{References}

1. Efstathiou E, Bozas G, Kostakopoulos A, Kastritis E, Deliveliotis C, et al. (2005) Combination of docetaxel, estramustine phosphate, and zoledronic acid in androgen-independent metastatic prostate cancer: efficacy, safety, and clinical benefit assessment. Urology 65: 126-130.

2. Martel CL, Gumerlock PH, Meyers FJ, Lara PN (2003) Current strategies in the management of hormone refractory prostate cancer. Cancer Treat Rev 29: 171-187.

3. Kyprianou N, Benning CM (2000) Suppression of human prostate cancer cell growth by alpha1-adrenoceptor antagonists doxazosin and terazosin via induction of apoptosis. Cancer Res 60: 4550-4555.

4. Benning CM, Kyprianou N (2002) Quinazoline-derived alpha1adrenoceptor antagonists induce prostate cancer cell apoptosis via an alpha1-adrenoceptor-independent action. Cancer Res 62: 597-602.

5. Yang H, Zonder JA, Dou QP (2009) Clinical development of novel proteasome inhibitors for cancer treatment. Expert Opin Investig Drugs 18: 957-971.

6. Adams J (2004) The proteasome: a suitable antineoplastic target. Nat Rev Cancer 4: 349-360.

7. Kirk CJ (2012) Discovery and development of second-generation proteasome inhibitors. Semin Hematol 49: 207-214.

8. Lum RT, Nelson MG, Joly A, Horsma AG, Lee G, et al. (1998) Selective inhibition of the chymotrypsin-like activity of the $20 \mathrm{~S}$ proteasome by 5 methoxy-1-indanone dipeptide benzamides. Bioorg Med Chem Lett 8: 209-214.

9. Papandreou CN, Logothetis CJ (2004) Bortezomib as a potential treatment for prostate cancer. Cancer Res 64: 5036-5043.

10. Bogyo M, McMaster JS, Gaczynska M, Tortorella D, Goldberg AL, et al. (1997) Covalent modification of the active site threonine of proteasomal beta subunits and the Escherichia coli homolog HslV by a new class of inhibitors. Proc Natl Acad Sci U S A 94: 6629-6634.

11. Baldisserotto A, Destro F, Vertuani G, Marastoni M, Gavioli R, et al (2009) N-terminal-prolonged vinyl ester-based peptides as selective proteasome betal subunit inhibitors. Bioorg Med Chem 17: 5535-5540.

12. Elofsson M, Splittgerber U, Myung J, Mohan R, Crews CM (1999) Towards subunit-specific proteasome inhibitors: synthesis and evaluation of peptide alpha',beta'-epoxyketones. Chem Biol 6: 811-822.
13. Zhou HJ, Aujay MA, Bennett MK, Dajee M, Demo SD, et al. (2009) Design and synthesis of an orally bioavailable and selective peptide epoxyketone proteasome inhibitor (PR-047). J Med Chem 52: 3028-3038.

14. Hanada M, Sugawara K, Kaneta K, Toda S, Nishiyama Y, et al. (1992) Epoxomicin, a new antitumor agent of microbial origin. J Antibiot (Tokyo) 45: 1746-1752.

15. Fu Y, Xu B, Zou X, Ma C, Yang X, et al. (2007) Design and synthesis of a novel class of furan-based molecules as potential $20 \mathrm{~S}$ proteasome inhibitors. Bioorg Med Chem Lett 17: 1102-1106.

16. Kyncl JJ (1993) Pharmacology of terazosin: an alpha 1-selective blocker. J Clin Pharmacol 33: 878-883.

17. Debruyne FM, Witjes WP, Fitzpatrick J, Kirby R, Kirk D, et al. (1996) The international terazosin trial: a multicentre study of the long-term efficacy and safety of terazosin in the treatment of benign prostatic hyperplasia. The ITT Group. Eur Urol 30: 369-376.

18. Kyprianou N, Benning CM (2000) Suppression of human prostate cancer cell growth by alpha1-adrenoceptor antagonists doxazosin and terazosin via induction of apoptosis. Cancer Res 60: 4550-4555.

19. Benning CM, Kyprianou N (2002) Quinazoline-derived alpha1adrenoceptor antagonists induce prostate cancer cell apoptosis via an alpha1-adrenoceptor-independent action. Cancer Res 62: 597-602.

20. Partin JV, Anglin IE, Kyprianou N (2003) Quinazoline-based alpha 1adrenoceptor antagonists induce prostate cancer cell apoptosis via TGFbeta signalling and I kappa B alpha induction. Br J Cancer 88: 1615-1621.

21. Walden PD, Globina Y, Nieder A (2004) Induction of anoikis by doxazosin in prostate cancer cells is associated with activation of caspase-3 and a reduction of focal adhesion kinase. Urol Res 32: 261-265.

22. Shaw YJ, Yang YT, Garrison JB, Kyprianou N, Chen CS (2004) Pharmacological exploitation of the alpha1-adrenoreceptor antagonist doxazosin to develop a novel class of antitumor agents that block intracellular protein kinase B/Akt activation. J Med Chem 47: 4453-4462.

23. Garrison JB, Kyprianou N (2006) Doxazosin induces apoptosis of benign and malignant prostate cells via a death receptor-mediated pathway. Cancer Res 66: 464-472.

24. Pan SL, Guh JH, Huang YW, Chern JW, Chou JY, et al. (2003) Identification of apoptotic and antiangiogenic activities of terazosin in human prostate cancer and endothelial cells. J Urol 169: 724-729.

25. Jin L, Qian X, Kulig E, Sanno N, Scheithauer BW, et al. (1997) Transforming growth factor-beta, transforming growth factor-beta receptor II, and p27Kip1 expression in nontumorous and neoplastic human pituitaries. Am J Pathol 151: 509-519.

26. Amit S, Ben-Neriah Y (2003) NF-kappaB activation in cancer: a challenge for ubiquitination- and proteasome-based therapeutic approach. Semin Cancer Biol 13: 15-28.

27. Xu K, Wang X, Ling M, Wong Y (2003) Growth inhibiting effects of terazosin on androgen-independent prostate cancer cell lines. Chin Med J (Engl) 116: 1673-1677.

28. Orlowski RZ, Stinchcombe TE, Mitchell BS, Shea TC, Baldwin AS, et al. (2002) Phase I trial of the proteasome inhibitor PS-341 in patients with refractory hematologic malignancies. J Clin Oncol 20: 4420-4427.

29. Masamha CP, Benbrook DM (2009) Cyclin D1 degradation is sufficient to induce G1 cell cycle arrest despite constitutive expression of cyclin E2 in ovarian cancer cells. Cancer Res 69: 6565-6572.

30. Albanese C, Johnson J, Watanabe G, Eklund N, Vu D, et al. (1995) Transforming p21ras mutants and c-Ets-2 activate the cyclin D1 promoter through distinguishable regions. J Biol Chem 270: 23589-23597.

31. Frezza M, Schmitt S, Dou QP (2011) Targeting the ubiquitin-proteasome pathway: an emerging concept in cancer therapy. Curr Top Med Chem 11: 2888-2905.

32. Sterz J, Jakob C, Kuckelkorn U, Heider U, Mieth M, et al. (2010) BSc2118 is a novel proteasome inhibitor with activity against multiple myeloma. Eur J Haematol 85: 99-107. 
Citation: Shujue Li\#, Wenzheng Wu\#, Weidong Ji\#, Yeping Liang\#, Lili Ou\#, Guohua Zeng*, Wenqi Wu* (2014) Terazosin Suppress Human Prostatic Cancer PC3 Cell Viability via Proteasome Inhibition. Biol Med 6: 203. doi:10.4172/0974-8369.1000203

Page 6 of 6

33. Mi L, Gan N, Chung FL (2011) Isothiocyanates inhibit proteasome activity and proliferation of multiple myeloma cells. Carcinogenesis 32: 216-223.

34. Shrivastava A, Gupta VB (2012) Various treatment options for benign prostatic hyperplasia: A current update. J Midlife Health 3: 10-19.

35. Cohen SA, Parsons JK (2012) Combination pharmacological therapies for the management of benign prostatic hyperplasia. Drugs Aging 29: 275-284.

36. Sherman JJ, Welch RW, Hill TM, McEwen C (2012) Prescriber monitoring for benign prostatic hyperplasia within a family medicine clinic: a comparison of medication classes. J Pharm Pract 25: 164-168.

37. Xiao H, Li HZ, Yang Y, Huang ZM, Li YQ, et al. (2007) [Clinical effectiveness and safety study of combined therapy with an alpha-blocker and an anticholinergic for patients with LUT/BPH]. Zhonghua Yi Xue Za Zhi 87: 1590-1593.

38. Chang KL, Cheng HL, Huang LW, Hsieh BS, Hu YC, et al. (2009) Combined effects of terazosin and genistein on a metastatic, hormoneindependent human prostate cancer cell line. Cancer Lett 276: 14-20.
39. Albeck JG, Burke JM, Aldridge BB, Zhang M, Lauffenburger DA, et al. (2008) Quantitative analysis of pathways controlling extrinsic apoptosis in single cells. Mol Cell 30: 11-25.

40. Landowski TH, Megli CJ, Nullmeyer KD, Lynch RM, Dorr RT (2005) Mitochondrial-mediated disregulation of $\mathrm{Ca} 2+$ is a critical determinant of Velcade (PS-341/bortezomib) cytotoxicity in myeloma cell lines. Cancer Res 65: 3828-3836.

41. Wang F, Zhai S, Liu X, Li L, Wu S, et al. (2011) A novel dithiocarbamate analogue with potentially decreased ALDH inhibition has copperdependent proteasome-inhibitory and apoptosis-inducing activity in human breast cancer cells. Cancer Lett 300: 87-95.

42. Belloni D, Veschini L, Foglieni C, Dell'Antonio G, Caligaris-Cappio F, et al. (2010) Bortezomib induces autophagic death in proliferating human endothelial cells. Exp Cell Res 316: 1010-1018. 